\title{
Preoperative predictors of low back surgery outcome: Preliminary six month review findings
}

\author{
Richard B Young PhD, Kenneth V Jones PhD
}

\author{
RB Young, KV Jones. \\ Preoperative predictors of low back surgery outcome: \\ Preliminary six month review findings. \\ Pain Res Manage 1999;4(4):189-199.
}

Research has shown that for patients undergoing low back surgery preoperative physical, psychological, and demographic and social information are predictive of outcome. However, some of the research findings have been conflicting, difficult to replicate and made questionable because of major methodological shortcomings. This study attempts to clarify further which preoperative variables best predict low back surgery outcome, using refined methodology. The sample comprised 140 patients ( 87 males, 53 females; age range 19 to 84 years; mean $\pm \mathrm{SD}, 48.5 \pm 15.4$ years) scheduled to undergo first-time low back surgery. Before surgery, patients were interviewed, and completed a comprehensive psychometric test battery. Perioperative information was collected on every patient. Outcome was assessed at six months following surgery, and surveyed patient pain levels, perceived pain relief, level of disability, return to work and analgesic use. Outcome was evaluated in terms of pain relief, and pain relief in conjunction with the level of disability, return to work status and analgesic use. Outcome was correlated with preoperative psychosocial variables alone. The variables found to be predictive of outcome included: compensation involvement; previous serious illness; having close family members who had experienced chronic pain; childhood hospitalization for serious illness; a nonorganic pain drawing; catastrophizing; depression; psychological maladjustment and psychological issues suspected by the interviewer. The preliminary findings suggest that preoperative psychosocial assessment is of great importance for first-time low back surgery outcome. Further follow-up of the study sample is required to confirm the reliability of findings.

Key Words: Low back surgery; Preoperative predictors

\section{Facteurs préopératoires de prévisibilité de l'issue d'une chirurgie lombaire : Résultats préliminaires après six mois}

RÉSUMÉ: La recherche a démontré que pour les patients qui subissent une chirurgie lombaire, certaines caractéristiques physiques, psychologiques, démographiques et sociales préopératoires constituent des facteurs de prévisibilité de l'issue du traitement. Par contre, certains résultats de recherche sont contradictoires, difficiles à reproduire et par conséquent douteux en raison de certaines lacunes importantes sur le plan méthodologique. Cette étude tente de clarifier davantage les variables préopératoires qui peuvent le mieux prédire l'issue de la chirurgie lombaire à l'aide d'une méthodologie raffinée. L'échantillon regroupait 140 patients (87 hommes, 53 femmes, âgés de 19 à 84 ans, moyenne \pm écart-type $48,5 \pm 15,4$ ans) devant subir une première chirurgie lombaire. Avant la chirurgie, les patients ont été interrogés et ont répondu à une batterie de questionnaires psychométriques complets. Les renseignements pré-opératoires ont été recueillis pour chaque patient. L'issue a été évaluée six mois après la chirurgie et on a noté le degré de douleur, le degré de soulagement perçu, le degré d'invalidité, le retour au travail et le recours aux analgésiques. L'issue a été évaluée sur le plan du soulagement de la douleur et du soulagement de la douleur en conjonction avec le degré d'invalidité, le retour au travail et le recours aux analgésiques. L'issue a aussi été mise en corrélation avec les variables psychosociales préopératoires seulement. Les variables qui ont exercé un rôle prédictif ont été les mécanismes compensatoires, les antécédents de maladie grave, le fait qu'un membre de la famille proche ait souffert de douleurs chroniques, l'hospitalisation pour maladie grave durant l'enfance, la douleur non organique, le catastrophisme, la dépression, la mésadaptation psychologique et les problèmes psychologiques soupçonnés par l'examinateur. Les résultats préliminaires donnent à penser qu'une évaluation psychosociale préopératoire serait d'une grande importance pour l'issue d'une première chirurgie lombaire. Il faudra procéder à un autre suivi de l'échantillon étudié pour confirmer la fiabilité de ces résultats.

Department of Psychological Medicine, Monash University, Clayton, Australia

Correspondence and reprints: Dr Richard B Young, Department of Psychological Medicine, Monash University, Monash Medical Centre, 246 Clayton

Road, Clayton, Victoria 3168, Australia.

Telephone: +011-613-9790 0196, fax +011-613-9790 0196

Received for publication August 13, 1999. Accepted October 4, 1999. 
L ow back pain disability is the most costly medical condition in industrialized countries, and is the number one cause of disability in people under 45 years of age (1-5). Effective treatment of such back problems is undermined by a lack of knowledge concerning this condition (6-8). In light of this fact, it is not surprising that some researchers have argued that most treatments aimed at preventing back problems or restoring function have been dismal failures (4). Certainly, in countries where back pain is compensable, failed treatment has carried a high price in terms of lost productivity, compensation payments and disability (9). This is an alarming fact because the incidence of low back pain and disability is increasing dramatically in Western countries (10).

Low back pain will affect over $60 \%$ of the population at some point in their lives. It is usually not associated with demonstrable pathology and, in the vast majority of cases, will resolve quickly and uneventfully (9). For patients who experience low back pain, approximately half are no longer disabled within two weeks; $70 \%$ have recovered within four weeks and within three to four months, $90 \%$ are pain free (11). For the patients who continue to experience symptoms, the majority will be disabled and off work at the end of one year, and most of these disabled individuals will continue to be disabled after two years (5). Chronic pain patients go on to have extensive and costly medical treatments, compensation benefits and legal awards which are quite disproportionate to the entire population of patients who suffer any form of low back problems (5).

In particular low back, sciatic, acute and, more frequently, chronic pain, are often treated with surgical intervention. However, such surgical intervention is not always followed by pain relief, even in cases where surgery is technically successful. Researchers therefore have attempted to account for such inconsistencies in outcome to differentiate patients who do well from those who do poorly. This process could allow surgeons to refine the selection and preparation of patients for lumbosacral surgery to maximize success rates. Such research has demonstrated that various preoperative demographic, social and especially psychological variables are significantly associated with surgery outcome (12). However, more research is required because the findings to date have been conflicting, difficult to replicate and have been questionable due to major flaws in study design (12). In addition, psychosocial concomitants of back pain treatment outcome have been neglected in favour of the clinical characteristics. Furthermore, in cases where psychosocial variables have been studied, few outcome studies have incorporated a wide enough array of standardized assessment measures to offer a critical comparison of the relative importance of clinical and psychosocial features in the prediction of treatment outcome (9). The same authors argued that for acute and subchronic low back pain, patient psychological status at presentation had a much stronger influence on outcome than clinical information gathered at the same time. This may also be the case for chronic low back pain.

Physical factors have been shown to be predictive of outcome, but in many cases physical findings, especially radio- graphic results, have proved unreliable (13). The majority of low back pain is poorly defined and physically unverifiable, and cannot be visualized or verified upon physical examination. The converse is also true. Jensen et al (14) reported significant spinal abnormality as evidenced by magnetic resonance imaging in asymptomatic patients. The incidence of positive radiographic findings for asymptomatic patients has also been reported by others $(7,15-17)$. The above points may explain why previous approaches that emphasized physical variables and neglected the nonphysical have generally been unsuccessful (4).

This study aims to clarify further which preoperative physical, psychological, and demographic and social variables predict lumbosacral surgery outcome using refined methodology. An attempt was made to incorporate suggestions made by researchers in the field which relate to the refinements of methodology, patient sampling, assessment, and follow-up measures and methods $(12,18)$. While variables from the physical and nonphysical domains are studied, the emphasis is on the nonphysical and especially the ability of psychological variables to predict low back surgery outcome.

It was hypothesized that patients who had successful surgery would differ significantly from those who did not, based upon a range of preoperative physical, psychological, and social and demographic variables.

The psychological variables that were measured preoperatively included psychological disturbance, anxiety, hostility, somatization, depression, coping, locus of control and hypochondriasis. Dispositional optimism was also assessed as a potential predictor variable, because Scheier et al (19) have found that this variable is a predictor of coronary artery bypass surgery outcome, and studies in the area of lumbar surgery suggest that pessimism/optimism may also be of significance in this area $(20,21)$. It was considered important to evaluate each variable as a predictor of outcome, to clarify how these variables combine to influence outcome and to observe how well the psychological tests used serve to predict patient response to treatment.

It is hoped that the results from the present study and other studies that use improved study designs can help to clarify further which patients are more likely to fare well from lumbar surgery, and perhaps to suggest ways for 'poor prospects' with good physical indications to be assisted before surgery so as to maximize the probability that they will benefit from lumbosacral surgical intervention.

\section{PATIENTS AND METHODS}

\section{Participants}

One hundred and forty-two first-time low back surgery candidates, who met eligibility criteria for this study during the one-year recruitment period (August 1, 1995 to July 31, 1996), were invited to participate in this study. Eligible patients were those who were about to undergo low back surgery for the first time; were not having the surgery as an emergency procedure (eg, cauda equina compression syndrome); had been experiencing low back and/or sciatic pain for at least 
three months before the scheduling of surgery; and who could understand the English language.

Of these, one declined to participate due to the perceived demands of the study, and one who agreed to participate in the study was interviewed the day before surgery but was unable to complete the presurgery assessment due to serious medical complications before surgery, and thus was excluded from the study. The remaining sample of 140 patients comprised 87 males (62.1\%) and 53 females (37.9\%); age ranged from 19 to 84 years (mean $\pm \mathrm{SD}, 48.5 \pm 15.4$ ).

\section{Measurement of preoperative variables}

Preoperative physical, psychological, and demographic and social variables were measured and/or recorded using a Presurgery Semistructured Interview, Low Back Surgery Patient Questionnaire and Surgeon Checklist.

Presurgery Semistructured Interview: The interview was designed by the first author. It included a large number of physical, psychological, and demographic and social variables that previous research has shown to be worthy of consideration for predicting low back surgery outcome, and/or were important to survey to describe fully the sample being studied. It is important to note that, the interview was semistructured. Patients, therefore, had more of an opportunity to describe their experiences with low back pain and disability, and personal histories. The variables surveyed in the instrument included: demographic information such as age and sex; relationship information such as marital status; family information such as number of children; existence of close family members with chronic pain or illness; occupational data; expectations of returning to work following surgery; compensation status; patient report of current complaint; substance and medication use; previous medical history (previous illness, pain or back problems) and interviewer observations.

Low Back Surgery Patient Questionnaire: This questionnaire was a battery of psychometric inventories outlined below and compiled to measure a number of preoperative variables of interest in this study.

The McGill Pain Questionnaire (MPQ) was used as a reliable measure of preoperative pain (22-25).

An adaptation of the Sickness Impact Profile (SIP) (26) was used in this study to measure preoperative patient reported disability level. The SIP is a 136-item instrument that was developed to provide a behaviourally based measure of sickness-related dysfunction. It has been reported to have good reliability and validity (27). This instrument is very lengthy, and it can be argued that the questionnaire has a large number of questions irrelevant to patients with low back pain (28). For this reason, the authors decided to use an adaptation based upon the questionnaire using 12 analogue scales, on which patients rate from 0 to $10(0-$ not at all, to 10 - a great deal) how much their low back condition, and the pain associated with it, affected them. The analogue scales surveyed the following categories: sleep and rest; emotional behaviour; body care and movement; home management; relationships; ambulation; communication; mobility; alertness behaviour; work; recreation and pastimes; and eating.

The Brief Symptom Inventory (BSI) (29) was used as a measure of psychological adjustment. The Global Severity Index was used to measure psychological maladjustment. The anxiety symptom dimension was used to measure preoperative anxiety, the hostility symptom dimension was used to measure preoperative hostility and the somatization symptom dimension was used to measure preoperative somatization in this study. The BSI and its dimensions have been shown to have good reliability and internal consistency, and good convergent, discriminant, construct and predictive validity $(29,30)$.

The Revised Life Orientation Test (LOT-R) (31) was used as a measure of dispositional optimism shown to have good reliability and internal consistency.

The Whiteley-7 Scale was used as a measure of preoperative hypochondriasis (32) with high internal validity and acceptable reliability.

The coping Strategies Questionnaire (CSQ) (33) was used as a measure of preoperative coping strategy. This questionnaire lists 42 strategies for coping with pain, which include six different cognitive strategies (diverting attention, reinterpreting pain sensations, coping self-statements, ignoring pain sensations, praying or hoping and catastrophizing) and one behavioural strategy (increasing activity level). This questionnaire has been shown to have satisfactory internal reliability (33). Patient scores on CSQ subscales were used instead of factor scores, because previous research has demonstrated inconsistency with regard to the factor structure of the CSQ (18).

The Zung Depression Scale (34) was used as a depression measure with adequate reliability and validity. Multidimensional Health Locus of Control scale (35) was used as a measure of preoperative internal locus of control, with established reliability and validity.

Pain drawing and Waddell's nonorganic signs test were used as measures of nonorganic pain signs and symptoms $(36,37)$. Pain drawings were assessed using the technique described by Uden et al (38), and used as reported by Chan et al (40). Excellent interevaluation reliability among both trained and untrained evaluators has been reported (39).

Expectations of pain relief were measured using three analogue scales ranging from 0 (no pain relief) to 10 (total pain relief). The first scale recorded expected back pain relief, the second leg pain relief and the third total pain relief.

Surgeon Checklist: The surgeon checklist was completed by surgeons before and after surgery on every patient in the study. It requested that for each patient surgeons note the following preoperative and intraoperative variables: surgeon's expectation of surgery outcome; motor function; sensory deficit; ankle jerk and knee jerk reflexes; diagnostic test results; whether prolapse was discovered at surgery; prolapse size; levels of surgery; intraoperative complications; postoperative complications; discharge diagnosis; type of surgery; fusion; and number of levels fused. Results from Waddell's Nonor- 
ganic signs test (38) were also noted by surgeons on this checklist.

\section{Measurement of postoperative and follow-up information}

Postoperative outcome variables were measured and/or recorded using the Follow-up Semistructured Interview and the Low Back Surgery Patient Follow-up Questionnaire six months following surgery.

Follow-up semistructured interview: This interview, designed by the first author, surveys a range of variables important to assess fully surgery outcome, includes the following: patient report of whether they have benefited from surgery; patient report of pain relief following surgery, including sites of pain or pain relief, duration of pain or pain relief, and nature of pain (constant or intermittent); patient estimation of the percentage of pain relief; employment details after surgery; compensation status; litigation status; postoperative treatment (if any); medication use; alcohol consumption; cigarette use; and additional observations or comments.

Low Back Surgery Patient Follow-up Questionnaire: Six months after surgery, patients completed the Low Back Surgery Patient Follow-up Questionnaire. This survey measured patient perceived pain using the MPQ and three pain relief analogue scales ranging from 0 (no pain relief) to 10 (total pain relief). On these three scales, patients were requested to indicate how much back, leg and total pain relief, respectively, they had experienced following surgery. Patient reported disability levels were measured postoperatively at follow-up using the adapted SIP analogue scales outlined earlier. Patients were requested to rate on an analogue scale how successful they felt surgery had been for them. This scale ranged from 0 (surgery not of any benefit) to 10 (surgery totally relieved pain). Patients were asked whether they would consider undergoing the procedure again, if necessary, and their comments were recorded on a analogue scale ranging from 0 (would definitely not have surgery) to 10 (would definitely have surgery).

\section{Procedure}

Patients being scheduled for first-time low back surgery during the one-year recruitment period were told by surgeons about the study and asked if they would agree to have researchers contact them. Patients were subsequently contacted via telephone, and the nature of the study was explained. If the patients agreed at this point to participate, the researcher scheduled a meeting with the patient in the ward upon admission on the day before surgery. All consenting patients took part in the preoperative interview and completed the preoperative questionnaire that same day.

Surgeons were asked to complete the Surgeon Checklist (outlined earlier) for all patients before and after surgery. Before surgery, surgeons were asked to note their expectations of surgery outcome, and were asked to perform Waddell's nonorganic signs test for each patient. After surgery, the surgeons completed all other checklist details.
Six months after surgery, the first author contacted patients via telephone to assess patient status. All patients were interviewed using the Follow-up Semistructured Interview, and were asked to complete the Low Back Surgery Followup Questionnaire. Further follow-up is planned at one year and annually thereafter for five years. The details on further follow-up are not available for this article.

\section{Statistical analysis}

Unless otherwise specified, all of the statistical procedures described in this section were performed using SPSS for Windows (SPSS for Windows, Chicago, Illinois).

Preliminary analysis of the outcome variables relating to postoperative pain relief and satisfaction with surgery was performed because it was expected that these variables would be highly correlated. To examine these inter-relationships, the variables were analyzed using Pearson product moment correlations. In addition to these correlations, a principal component analysis using Varimax rotation (40) was performed on these variables, to clarify whether they would, as expected, fall upon one and only one component. Further clarification of the inter-relationships was undertaken by analyzing the z-transformations of these outcome variables using Cronbach's alpha $(41,42)$ - a technique for measuring the degree of internal consistency, and hence whether the variables appeared to be a coherent measure of pain relief or surgery success. Z-transformations were employed to reduce differences in scale between the variables. As expected, these variables were shown to be highly interrelated, and therefore arguably measured the same (or highly related) concepts (pain relief or satisfaction with surgery). The z-transformed postoperative pain relief and satisfaction with surgery variable scores for all patients on each variable were summed to produce the dependent (outcome) variable, largely reflecting pain relief, called TOTALZ.

Each patient in the sample was classified into one of three groups, which reflected good, fair or poor surgery outcome, according to the patient's status on the four postoperative variables of reported pain relief, disability, return to usual work or activity and medication use. This rating system has been used a number of times in previous studies (43-50), and is derived from the Mayo Clinic's rating system. Pain relief was based upon the total pain relief score derived from each patient's estimate of pain relief as reported in the follow-up questionnaire and interview. Restriction of physical activity was based upon the patient's perceived level of disability reported in the follow-up questionnaire. Return to work or activity and medication use were clarified at the follow-up interview. This system is based upon the following criteria.

Good - over $75 \%$ relief of back and leg pain, return to usual work, occasional mild or no analgesic medication, and minimal or no restrictions to physical activity

Fair $-26 \%$ to $75 \%$ relief of back and leg pain, return to less strenuous work, regular use of mild (non-narcotic) 
TABLE 1

Physical characteristics of patients having low back surgery

\begin{tabular}{|c|c|c|}
\hline Variable & Number & $\begin{array}{l}\text { Percentage of total } \\
\qquad(n=140)\end{array}$ \\
\hline Surgery at one level & 86 & 61.4 \\
\hline Surgery at two levels & 35 & 25.0 \\
\hline Surgery at three levels & 14 & 10.0 \\
\hline Surgery at four levels & 5 & 3.6 \\
\hline Surgery at L1L2 & 0 & 0 \\
\hline Surgery at L2L3 & 6 & 4.3 \\
\hline Surgery at L3L4 & 29 & 20.7 \\
\hline Surgery at L4L5 & 96 & 68.6 \\
\hline Surgery at L5S1 & 86 & 61.4 \\
\hline \multicolumn{3}{|l|}{ Diagnoses* } \\
\hline Scoliosis & 2 & 1.4 \\
\hline Osteoarthritis & 8 & 5.7 \\
\hline Prolapsed lumbar disc & 67 & 47.9 \\
\hline Spondylolysis & 9 & 6.4 \\
\hline Spondylolisthesis & 26 & 18.6 \\
\hline Spinal stenosis & 46 & 32.9 \\
\hline Other & 18 & 12.9 \\
\hline \multicolumn{3}{|l|}{ Operative procedure $^{+}$} \\
\hline Laminectomy & 82 & 58.6 \\
\hline Discectomy & 63 & 45.0 \\
\hline Fusion & 60 & 42.9 \\
\hline
\end{tabular}

*In this category, patients could have concurrent diagnosis; ${ }^{\dagger}$ In this category, patients could have undergone more than one procedure during surgery

analgesic medication and moderate physical activity restriction

Poor $-0 \%$ to $25 \%$ relief or worsening of back and leg pain, no return to work, occasional or regular use of strong (narcotic) analgesic medication, and severe restrictions to physical activity

Note that the outcome rating was determined by the most impaired rating in any category.

Patient classification into one of these three groups, provided a dependent (outcome) variable relating to a combination of important outcome criteria (pain relief, disability, return to work, medication use), and was labelled OUTCOME2. In addition, the three categories were reduced to two groups, comprising the good and a combination of fair or poor categories, producing a variable reflecting a binary grouping of successful versus unsuccessful outcome. This variable was labelled DICHOT2.

A review of the Preoperative Low Back Surgery Patient Questionnaire, Presurgery Semistructured Interview, and Surgeon Checklist was completed to clarify the variables to be used in subsequent regression analyses. Some variables were deleted from the outset for various reasons, eg, if all patients responded in the same way for a particular item. The remain-
TABLE 2

Means and standard deviations for preoperative psychometric inventory measures of patients having low back surgery

\begin{tabular}{lccc} 
Measure & Score range & Mean & $\begin{array}{c}\text { Standard } \\
\text { deviation }\end{array}$ \\
\hline $\begin{array}{l}\text { Psychological } \\
\text { Maladjustment } \\
\text { (BSI) }\end{array}$ & $33-80^{*}$ & 62.4 & 15.7 \\
Somatisation (BSI) & $41-80$ & 64.1 & 12.2 \\
Anxiety (BSI) & $38-80$ & 61.1 & 15.5 \\
Hostility (BSI) & $39-80$ & 57.9 & 14.0 \\
Optimism (LOT-R) & $0-24^{\dagger}$ & 13.8 & 5.4 \\
Hypochondriasis & $0-7^{\ddagger}$ & 2.4 & 2.2 \\
$\quad$ Whiteley-7) & & & \\
$\begin{array}{l}\text { Depression (Zung) } \\
\text { Internal Locus of } \\
\text { Control (MHLC) }\end{array}$ & $25-100^{\S}$ & 54.0 & 14.1 \\
\hline
\end{tabular}

*For each symptom dimension the global severity index (GSI) of the brief symptom inventory (BSI), raw scores are converted to $T$ scores using the available published norms (29). For the present study, the adult nonpatient norms were used to calculate patient T scores. The score on each of these BSI dimensions that will serve in a selection model to define a positive case for that dimension is generally a $T$ score greater than or equal to 63 (29). However, it is acknowledged that the generalizability of this decision rule has not been fully explored (29). The higher the $T$ score, the more the respondent experiences symptoms as measured on the symptom dimension. ${ }^{+}$The higher the score, the more optimistic the respondent. The higher the score, the more hypochondriacal the respondent. ${ }^{5}$ The higher the score, the more depressed the respondent. "The higher the score, the more internal the respondent's locus of control. LOT-R Revised Life Orientation Test; MHLC Multidimensional Health Locus of Control; Whiteley-7 Whiteley-7 scale a measure of hypochondriasis; Zung Zung depression scale

ing independent variables recorded categorically were then transformed to produce $\mathrm{k}-1$ (where $\mathrm{k}$ is the number of categories) binary or 'dummy' variables according to the procedure of Cohen and Cohen (51) for subsequent data analysis.

Correlation coefficients were calculated to measure the correlations between TOTALZ, OUTCOME2 and DICHOT2, and all the remaining independent variables. Of these, only independent variables with statistically significant correlations with the dependent variable in question ( $\mathrm{P}$ 0.05)were employed in the regression analyses.

TOTALZ was used as the dependent (outcome) variable in hierarchical multiple linear regression analyses (51). In addition to entering the independent variables significantly correlated with this dependent variable (P 0.05), preoperative pain and disability measures were entered first into the regression equation to clarify how much of the variance in TOTALZ could be accounted for by these two variables.

Because the variable OUTCOME2 may be said to be measured on an ordinal scale (good, fair, poor), maximum likelihood ordered logit regression $(52,53)$ was employed. This technique is similar to logistic regression and multinomial or polytomous logistic regression $(53,54)$ except that the former allows only binary outcomes and the latter allows multinomial (eg, unordered) outcomes.

An hierarchical ordered logit regression was carried out 
TABLE 3

Means and standard deviations for the preoperative coping strategies questionnaire subscales and effectiveness ratings for patients having low back surgery

\begin{tabular}{|c|c|c|c|}
\hline Subscale & Score range & Mean & $\begin{array}{l}\text { Standard } \\
\text { deviation }\end{array}$ \\
\hline Diverting attention & $0-36^{*}$ & 12.2 & 7.7 \\
\hline $\begin{array}{l}\text { Reinterpreting pain } \\
\text { sensations }\end{array}$ & $0-36$ & 6.0 & 6.2 \\
\hline $\begin{array}{l}\text { Coping self } \\
\text { statements }\end{array}$ & $0-36$ & 21.7 & 7.0 \\
\hline $\begin{array}{l}\text { Ignoring pain } \\
\text { sensation }\end{array}$ & $0-36$ & 14.3 & 8.1 \\
\hline Praying and hoping & $0-36$ & 16.8 & 8.0 \\
\hline Catastrophizing & $0-36$ & 12.9 & 9.6 \\
\hline $\begin{array}{l}\text { Increasing activity } \\
\text { level }\end{array}$ & $0-36$ & 14.7 & 6.1 \\
\hline \multicolumn{4}{|l|}{ Effectiveness ratings } \\
\hline $\begin{array}{l}\text { Perceived control } \\
\text { over pain }\end{array}$ & $0-6^{+}$ & 2.9 & 1.3 \\
\hline $\begin{array}{l}\text { Perceived ability to } \\
\text { decrease pain }\end{array}$ & $0-6^{\ddagger}$ & 2.9 & 1.2 \\
\hline
\end{tabular}

using the Stata package (Stata Statistical Software, College Station, Texas). Using the variables subsequently selected by this procedure to predict OUTCOME2, a classification accuracy (classification of patients into good, fair, or poor groups) in nonchance corrected and chance corrected kappa percentage terms $(55,56)$ were given. Selection of independent variables for this regression analysis was based upon significant (P 0.05) correlation coefficients.

Finally, hierarchical logistic regression analysis (54) was used for DICHOT2 to attempt to predict group membership into these two groups reflecting successful versus unsuccessful outcome, respectively. Selection of independent variables for this regression analysis was again based upon significant $(\mathrm{P}=0.05)$ correlation coefficients.

\section{RESULTS}

Preoperative patient characteristics are presented in the Tables 1 to 4 and describe the study sample in detail.

\section{First follow-up (six months postoperative), and data and statistical analysis}

Six months following surgery, complete outcome data were obtained for the entire sample (100\%).

Dependent variables: The preliminary analysis of the set of dependent variables relating to postoperative pain relief and satisfaction with surgery (back pain relief, leg pain relief, total pain relief, patient perceived success of surgery, patient preparedness to make the same decision for surgery again, estimated total pain relief at interview) revealed statistically significant $(\mathrm{P}=0.05)$ Pearson product moment correlations.

Principal component analysis (41) of these variables indi-
TABLE 4

Psychological characteristics of sample as surveyed by interviewer, surgeon and pain drawing for patients undergoing low back surgery

\begin{tabular}{|c|c|c|}
\hline Measure & Number & $\begin{array}{l}\text { Percentage of } \\
\text { total }(n=140)\end{array}$ \\
\hline $\begin{array}{l}\text { Abnormal mood observed at } \\
\text { interview }\end{array}$ & 35 & 25.0 \\
\hline $\begin{array}{l}\text { Abnormal demeanour observed } \\
\text { at interview }\end{array}$ & 11 & 7.9 \\
\hline $\begin{array}{l}\text { Other psychological issues } \\
\text { suspected by interviewer }\end{array}$ & 50 & 35.7 \\
\hline Nonorganic pain drawing & 18 & 12.9 \\
\hline $\begin{array}{c}\text { Clinically significant nonorganic signs } \\
\text { on Waddell's nonorganic signs } \\
\text { test (greater than or equal to 3) }\end{array}$ & 8 & 5.7 \\
\hline
\end{tabular}

cated that all variables loaded on one factor, with high factor loading (greater than 0.7 in all cases). Varimax rotation was not possible because only a one-factor solution was extracted.

The z-transformations of these dependent variables were analyzed using Cronbach's alpha $(41,42)$. As mentioned earlier, z-transformations were required because of the differences of scale between the variables. These items had a coefficient alpha of 0.9521 , which indicated a high degree of internal consistency and suggested that these items taken together appear to be a coherent measure of pain relief or surgery success. Because these variables were shown to be highly interrelated, and arguably measured essentially the same concept (pain relief or satisfaction with surgery), the variables were combined into one composite variable for subsequent multiple regression. The dependent variable scores for all patients on each individual dependent variable were transformed into $\mathrm{z}$ scores and summed to produce the variable TOTALZ.

All patients were classified at follow-up into the three groups outlined above. The good outcome group comprised 63 patients ( $45 \%$ of total sample), the fair group 31 patients $(22.1 \%)$ and the poor group 46 patients $(32.9 \%)$. The resulting group variable was labelled OUTCOME2, which was also used as a dependent variable for subsequent regression analysis.

Independent variables: Review of all independent variables for missing data indicated that the following variables contained missing data (the amount of which is indicated in parentheses): optimism (five patients); internal locus of control (two patients); all CSQ subscales (three patients); radiographic results (32 patients); computer assisted tomography scan results (20 patients); magnetic resonance imaging results (76 patients); myelography results (103 patients); discography results (113 patients); other diagnostic test results (138 patients); prolapse found at surgery, if any (73 patients); size of prolapse, if applicable (73 patients); occupation type variables (40 patients); time off work before surgery (47 patients); job satisfaction variables (40 patients); job financial satisfaction variables (40 patients); expectation of return to 
TABLE 5

Summary of hierarchical regression analysis for variables predicting TOTALZ $(n=140)$ for patients undergoing low back surgery

\begin{tabular}{|c|c|c|c|}
\hline Variable & $\begin{array}{c}\text { Unstandardized } \\
\text { regression } \\
\text { coefficient-B }\end{array}$ & $\begin{array}{c}\text { Standard } \\
\text { error of } \\
\text { B } \\
\end{array}$ & $\begin{array}{c}\text { Standardized } \\
\text { regression } \\
\text { coefficient }\end{array}$ \\
\hline Baseline pain measure & 0.02 & 0.03 & 0.05 \\
\hline $\begin{array}{l}\text { Baseline disability } \\
\text { measure }\end{array}$ & -0.01 & 0.02 & -0.04 \\
\hline $\begin{array}{l}\text { Compensation } \\
\text { involvement }\end{array}$ & 3.04 & 0.73 & $0.28^{*}$ \\
\hline Previous serious illness & 1.84 & 0.69 & $0.17^{\dagger}$ \\
\hline $\begin{array}{l}\text { Close family members } \\
\text { with chronic pain }\end{array}$ & 1.86 & 0.66 & $0.17^{\dagger}$ \\
\hline $\begin{array}{l}\text { Childhood } \\
\text { hospitalization for } \\
\text { serious illness }\end{array}$ & 1.96 & 0.84 & $0.15^{\ddagger}$ \\
\hline Pain Drawing & -3.41 & 1.08 & $-0.21^{\dagger}$ \\
\hline $\begin{array}{l}\text { Catastrophizing subscale } \\
\quad \text { (CSQ) }\end{array}$ & -0.16 & 0.04 & $-0.29 *$ \\
\hline $\begin{array}{l}\text { Psychological issues } \\
\text { suspected at } \\
\text { interview }\end{array}$ & 1.67 & 0.76 & $0.15^{\ddagger}$ \\
\hline
\end{tabular}

work following surgery variables (35 patients) and relationship description variables (36 patients). Diagnostic test results were highly variable because patients with different conditions, and seeing different surgeons, received different test procedures. Due to the extensive missing data for these variables, they were deleted from subsequent analysis. These occupational variables were hence deleted from subsequent regression analyses to avoid the problems associated with such a large proportion of missing data. The amount of missing data for optimism, locus of control and coping was not extensive, and these variables were, therefore, retained for regression analyses.

Following the calculation of correlation coefficients between each regression dependent variable (TOTALZ, OUTCOME2 and DICHOT2) and all the remaining independent variables, a further reduction of the number of independent variables entered into regression analyses occurred by subsequently excluding from entry into the regression equations all independent variables with a nonsignificant $(\mathrm{P}>0.05)$ correlation with the dependent variable in question.

\section{Multivariate (regression) data analysis}

Hierarchical multiple regression analyses for TOTALZ: Hierarchical multiple regression analyses (52) were performed using TOTALZ as the dependent variable and using the independent variables as outlined above. Although baseline pain and disability measures did not have significant regression (B) coefficients, they were retained for theoretical reasons. This procedure resulted in the selection of nine variables (including the retained PAIN1 and DISABIL1), which together accounted for $52.78 \%$ of the variance (adjusted
TABLE 6

Summary of maximum likelihood ordered logit regression analysis for variables predicting OUTCOME2 $(n=140) *$ for patients undergoing low back surgery

\begin{tabular}{lccc} 
Variable & $\begin{array}{c}\text { Beta } \\
\text { coefficient }\end{array}$ & $\begin{array}{c}\text { Standard } \\
\text { error }\end{array}$ & Z statistic \\
\hline Compensation involvement & 1.35 & 0.40 & $3.36^{\dagger}$ \\
Previous serious illness & 1.43 & 0.40 & $3.54^{\dagger}$ \\
Zung Depression Score & -0.08 & 0.02 & $-3.78^{\dagger}$ \\
Psychological issues & 1.14 & 0.42 & $2.72^{\ddagger}$ \\
$\quad$ suspected at interview & & & \\
\hline${ }^{*}$ No change statistics are derived in this type of analysis; ${ }^{+} P \leq 0.001 ;{ }^{*} P \leq 0.01$
\end{tabular}

TABLE 7

Summary of actual group membership versus predicted group membership based upon maximum likelihood ordered logit regression solution $(n=140)$ for patients undergoing low back surgery

\begin{tabular}{lccc} 
& \multicolumn{3}{c}{ Predicted Group Membership } \\
Actual group membership & Good & Fair & Poor \\
\hline Good & 54 & 2 & 7 \\
Fair & 19 & 0 & 12 \\
Poor & 6 & 1 & 39 \\
\hline
\end{tabular}

TABLE 8

Summary of logistic regression analysis for variables predicting good versus fair/poor outcome $(n=140)$ for patients undergoing low back surgery

\begin{tabular}{|c|c|c|c|}
\hline Variable & $\begin{array}{l}\text { Unstandardized } \\
\text { regression } \\
\text { coefficient }\end{array}$ & $\begin{array}{l}\text { Standard } \\
\text { error of B }\end{array}$ & Wald statistic \\
\hline $\begin{array}{c}\text { Compensation } \\
\text { involvement }\end{array}$ & 1.28 & 0.47 & $7.40^{*}$ \\
\hline $\begin{array}{l}\text { Previous serious } \\
\text { illness }\end{array}$ & 1.23 & 0.46 & $7.07^{*}$ \\
\hline $\begin{array}{l}\text { Zung Depression } \\
\text { Score }\end{array}$ & -0.08 & 0.02 & $9.69^{\dagger}$ \\
\hline $\begin{array}{l}\text { Psychological } \\
\text { issues suspected } \\
\text { at interview }\end{array}$ & 1.32 & 0.51 & $6.71^{*}$ \\
\hline${ }^{*} P \leq 0.01 ;{ }^{+} P \leq 0.001$ & & & \\
\hline
\end{tabular}

Hierarchical ordered logit regression analyses for OUTCOME2: Hierarchical ordered logit regression yielded four variables (presurgery pain and disability measures were not retained using this procedure) (Table 6). Using these four variables to predict OUTCOME2 gave a classification accuracy (classification into good, fair, poor) of $66.43 \%$ (kappa $=0.45, Z=7.30, \mathrm{P}<0.0001, \mathrm{rho}^{2}$ 0.41) (Table 7). A squared Spearman's rho, a nonparametric correlation coefficient for ordinal data (57), provides a statistic that is a form of equivalent to the percentage of variance explained by the so- 
TABLE 9

Summary of actual group membership versus predicted group membership based upon logistic regression solution $(n=140)$ for patients undergoing low back surgery

\begin{tabular}{|c|c|c|}
\hline \multirow[b]{2}{*}{ Actual group membership } & \multicolumn{2}{|c|}{ Predicted group membership } \\
\hline & Good & Fair/poor \\
\hline Good & 50 & 13 \\
\hline Fair/Poor & 14 & 63 \\
\hline
\end{tabular}

lution; ie, a rho ${ }^{2}$ of 0.41 denotes that approximately $41 \%$ of the variance in outcome is explained by the regression equation.

\section{Logistic regression analysis for DICHOT2}

Hierarchical logistic regression analysis was conducted on DICHOT2. This procedure yielded four variables (presurgery pain and disability measures were not retained using this procedure) (Table 8). Using these four variables to predict patient membership of the two groups gave a classification accuracy (classification into good, fair or poor groups) of $80.71 \%\left(\mathrm{kappa}=0.61, \mathrm{P}<0.0001, \mathrm{phi}^{2}\right.$ (equivalent to $\left.\mathrm{R}^{2}\right)=0.37$ ) (Table 9).

\section{DISCUSSION}

Six months after surgery patients who had successful lumbar surgery could be distinguished from those who did not, based upon a combination of preoperative variables. This was the case when outcome was conceptualized in terms of pain relief (TOTALZ) and a composite outcome variable that considered pain relief in conjunction with perceived level of disability, return to work or activity and medication use (OUTCOME2/DICHOT2).

\section{Multiple regression analyses of outcome as conceptualized by pain relief}

Six months following surgery, patient pain relief was significantly and inversely associated with compensation involvement, previous serious illness, close family members with chronic pain, childhood hospitalization for serious illness, pain drawing, catastrophizing and psychological issues suspected at interview. More specifically, greater pain relief was associated with no compensation involvement; having had no previous serious illnesses; having no family members with chronic pain; having had no childhood hospitalizations for serious illness; an anatomically consistent pain drawing; lower catastrophizing as measured by the catastrophizing subscale of the CSQ; and no psychological issues being suspected during the assessment interview. These variables (including nonsignificant preoperative pain and disability levels) accounted for $52.78 \%$ of the variance in pain relief at six months following surgery.

\section{Regression analyses of outcome as conceptualized by pain relief, perceived disability, return to work or activity and medication use}

Six months following surgery, outcome as measured by membership in the good, fair or poor groups could be predicted using a regression equation comprising four variables: compensation involvement; previous serious illness; Zung depression score; and psychological issues suspected at interview. Prediction of better outcome was associated with no compensation involvement, no previous serious illness, a lower depression score and no psychological issues being suspected at interview. Using these four variables to predict outcome in this way resulted in a classification accuracy of $66.43 \%$.

When outcome at the six-month review was compressed into the binary classification of good versus fair or poor, outcome was predicted by four variables with a classification accuracy of $80.71 \%$. At this review, the variables selected by this procedure were the same as those selected for the threecategory outcome classification of patients at the six-month review as mentioned above.

\section{General discussion of multivariate results}

Compensation involvement was associated with poorer outcome whether outcome was conceptualized in terms of pain relief, or in terms of pain relief in conjunction with patient reported disability, return to work or activity status and medication use. This strong association is clearly in agreement with the bulk of previous research reviewed by Young (12), which has shown compensation to be associated with poorer outcomes in patients who have undergone low back surgery.

In this study, no physical variable was significantly associated with outcome in the regression analyses. Other researchers have noted that physical factors including diagnostic tests such as myelography were unable to predict outcome following low back surgery (58). In the present study, all radiographic results were deleted from multivariate analysis from the outset because of the large amounts of missing data for each test. It could, therefore, be argued that this finding is related to the heterogeneous nature of the sample in this study. More specifically, this study surveyed preoperative status and subsequent outcome for patient with a variety of different conditions (ie, scoliosis, osteoarthritis, prolapsed lumbar disc, spondylolysis, spondylolisthesis and spinal stenosis) requiring different procedures of laminectomy, discectomy and/or lumbar fusion. The preoperative physical factors important to outcome may be somewhat different for each category. Therefore, when these groups are combined, variables that may have reached significance if only one diagnostic group was analyzed may have lost their significance.

While some important preoperative physical variables may have been made statistically nonsignificant due to the study design, the importance of psychosocial variables and outcome remains clear. It must be conceded, however, that the heterogeneous sample may have biased results in this way, thus previous research reporting physical predictors of outcome cannot be ignored.

\section{Limitations of this study}

The results of this study are correlational and can, therefore, be useful in inferring association. However, no cause and effect conclusions on relationships between the variables 
can be drawn. For causal relationships to be clarified, further research is required. With coping strategies, for example, it is not clear whether the use of certain strategies leads to greater pain and disability, or whether greater pain and disability lead to the use of certain strategies (59). This is because studies to date have generally been correlational in nature. The same is true for all other variables found to be significantly associated with outcome.

Another weakness of this study is the deletion of the following variables from subsequent regression analyses due to extensive missing data: occupation type; time off work before surgery; job satisfaction; job financial satisfaction; and expectations of return to work following surgery. It could be argued that these variables are of great predictive relevance for low back surgery outcome (J A Turner, personal communication, March, 1995). Waddell et al (60) also found in a prospective study that return to work following low back surgery was influenced predominantly by occupational status. Other researchers, however, have also been unable to analyze fully occupational variables and outcome because of sample heterogeneity of working patterns and variation in occupational status (9).

This study sought to use a refined methodology. It must be conceded, however, that the study has some methodological flaws. The first author conducted both preoperative assessments and outcome interviews. Therefore, the interviewer was not blind to the hypothesis of the intervention, nor to the preoperative psychological status of the patient. This may have biased the results to a degree that cannot be known. Bessette et al (61) argued that in surgery, research assessment by interview should occur with interviewers blind to the hypothesis of the intervention. In defense of the present study's methodology, however, the follow-up information was collected and analyzed by someone other than the operating surgeon (as recommended by Waddell) (62); as a result bias would have been reduced to some degree.

Another important issue in orthopaedic surgical studies is that the recommended minimum observation period is two years (61-63). While the results presented here only pertain to a six-month review, further follow-up is in progress.

\section{CONCLUSIONS}

Outcome in this study was explained by psychosocial variables alone. Some physical parameters may have been poor predictors because of the present study's methodology and design; however, the highly significant prediction of outcome from psychosocial features is noteworthy. Other researchers have also found that prediction of outcome could be based upon psychosocial variables alone (58).

Based upon the present findings, future research should attempt to construct a preoperative surgery assessment device to identify patients who may be at risk for poorer outcome and who need psychological treatment before surgery. Other researchers have more recently attempted to construct tools to survey preoperative status and outcome $(9,64)$, partly in an endeavour to select appropriate patients for surgery and partly to allow for comparisons of treatment outcome. It is beyond the scope of this study to begin the task of a preoperative assessment tool construction, because the outcome for the sample under scrutiny has only been measured at the six-month postoperative point and the recommended minimum observation period following surgery is two years (61-63). The promising early findings need to be replicated at subsequent follow-up. If they prove to be reliable, the construction of an assessment device can proceed.

Previous research and a recent monograph on preoperative screening for chronic pain patients (65) highlight the importance of preoperative chronic pain patient assessment. The results of this study also clearly point to the importance of routine preoperative psychological assessment.

While this study has been able to predict accurately low back surgery outcome using preoperative information, it is unlikely that any form of preoperative assessment could do this with complete accuracy. Low back surgery candidates are influenced by a complex interaction of physical, psychological, and social and demographic factors that are not yet fully understood. There may always be patients with good preoperative indications who have poor outcome and, probably less frequently, patients who do well despite a preoperative profile suggesting that a poorer outcome is likely. Researchers can only strive for the most accurate assessment device possible, while taking into account time and financial restrictions for any form of preoperative assessment.

Further follow-up of the sample of patients used in this study is required to confirm the reliability of the results. Future research should then attempt to construct a simple and brief preoperative screening tool that identifies as accurately as possible the patients who are at risk for poor surgery outcome. Such research will also need to clarify whether preoperative psychological treatment for psychologically distressed patients does indeed result in improved surgical outcome.

ACKNOWLEDGEMENTS: The authors wish to thank Professor George Mendelson and Mr Neil Cullen FRACS for their review of this article before publication.

\section{REFERENCES}

1. Kelsey JL, White AA. Epidemiology and impact of low back pain. Spine 1980;5:133-42.

2. Nachemson AL, Bigos SJ. The low back. In: Cruess RL, Rennie WRJ, eds. Adult Orthopaedics, vol 2. New York: Churchill Livingstone, 1984:843-937.

3. Spengler DM, Bigos SJ, Martin NA, Zelt J, Fisher L, Nachemson A. Back injuries in industry: a retrospective study, overview and cost analysis. Spine 1986;11:241-5.

4. Bigos SJ, Battie MC, Spengler DM, et al. A longitudinal, prospective study of industrial back injury reporting. Clin Orthopaed Rel Res 1992;279:21-34.

5. Gatchel RJ, Polantin PB, Mayer TG. The dominant role of psychosocial risk factors in the development of chronic low back pain disability. Spine 1995;20:2702-9.

6. Nachemson AL. The lumbar spine: an orthopaedic challenge. Spine 1976;1:59-64.

7. Weisel SW, Feffer HL, Rothman RH. Industrial low back - a 
prospective evaluation of a standardised diagnostic and treatment protocol. Spine 1984;9:549-91.

8. Hadler NM. The predicament of backache. J Occup Med 1988;30:449-52.

9. Burton AK, Tillotson KM, Main CJ, Hollis S. Psychosocial predictors of outcome in acute and subchronic low back trouble. Spine 1995;20:722-8.

10. Waddell G. Biopsychosocial analysis of low back pain. In: Nordin M, Vischler TL, eds. Bailliere's Clinical Rheumatology, vol 6. London: Bailliere Tindall, 1992:523-57.

11. Mayer TG, Gatchel RJ. Functional Restoration for Spinal Disorders: The Sport's Medicine Approach. Philadelphia: Lea \& Febiger, 1988.

12. Young RB. Preoperative and intraoperative predictors of lumbosacral surgery outcome: a literature review. Pain Rev 1996;3:203-19.

13. McCreary CP, Turner J, Dawson E. The MMPI as a predictor of response to conservative treatment for low back pain. J Clin Psychol 1979;35:278-84.

14. Jensen MC, Brant-Zawadzki MN, Obuchowski N, et al. Magnetic resonance imaging in the lumbar spine in people without back pain. N Engl J Med 1994;331:69-73.

15. Herron LD, Turner JA, Novell LA, Kreif SL. Patient selection for lumbar discectomy with a revised objective rating system. Clin Orthopaed Rel Res 1996;325:148-55.

16. Boden SD, Davis DO, Dina TS, et al. Abnormal magnetic resonance scans of the lumbar spine in asymptomatic patients. A prospective investigation. J Bone Joint Surg 1990;72:403-8.

17. Hitselberger W, Whitten R. Abnormal myelograms in asymptomatic patients. J Neurosurg 1968;28:204-6.

18. Young RB. Preoperative physical, psychological and demographic/social predictors of lumbosacral surgery outcome. Phd Manuscript. Monash University. 1998.

19. Scheier MF, Magovern GJ, Abbott RA, et al. Dispositional optimism and recovery from coronary artery bypass surgery: the beneficial effects on physical and psychological well-being. J Pers Soc Psychol 1989;57:1024-40.

20. Hurme M, Alaranta H. Factors predicting the result of surgery for lumbar intervertebral disc herniation. Spine 1987;12:933-8.

21. Herron LD, Turner J, Clancy S, Weiner P. The differential utility of the Minnesota Multiphasic Personality Inventory. A predictor of outcome in lumbar laminectomy for disc herniation versus spinal stenosis. Spine 1986;11:847-50.

22. Melzack R. The McGill Pain Questionnaire: major properties and scoring methods. Pain 1975;1:277-99.

23. Syrjala KL, Chapman CR. Measurement of clinical pain: a review and integration of research findings. In: Benedetti C, Chapman CR, Moricca G, eds. Advances in Pain Research and Therapy: Recent Advances in the Management of Pain, vol 7. New York: Raven Press, 1984:257-96.

24. Masson EA, Hunt L, Gem JM, Boulton AJM. A novel approach to the diagnosis and assessment of symptomatic diabetic neuropathy. Pain 1989;38:25-8.

25. Melzack R, Terrence C, Fromm G, Amsel R. Trigeminal neuralgia and atypical facial pain: use of the McGill Pain Questionnaire for discrimination and diagnosis. Pain 1986;27:297-302.

26. Bergner M, Bobbitt RA, Carter WB, Gibson BS. The Sickness Impact Profile: development and final revision of a health status measure. Med Care 1981;19:787-805.

27. Romano JM, Turner JA, Jensen MP. The Chronic Illness Problem Inventory as a measure of dysfunction in chronic pain patients. Pain 1992;49:71-5.

28. Thomas AMC. The spine. In: Pynsent P, Fairbank J, Carr A, eds. Outcome Measures in Orthopaedics. London: Butterworth Heinemann, 1993:50-100.

29. Derogatis LR. Brief Symptom Inventory: Administration Scoring and Procedures Manual. Minneapolis, MN: National Computer Systems Inc, 1993.

30. Croog SH, Levine S, Testa MA, et al. The effects of antihypertensive therapy on quality of life. N Engl J Med 1986;314:1657-64.
31. Scheier MF, Carver CS, Bridges MW. Distinguishing optimism from neuroticism (and trait anxiety, self-mastery, and self-esteem): a reevaluation of the Life Orientation Test. J Pers Soc Psychol 1994;67:1063-78.

32. Fink P, Ewald H, Jensen J, et al. Screening for somatization and hypochondriasis in primary care and neurological inpatients. A seven-item scale for hypochondriasis and somatization. J Psychosom Res 1999:46:261-73.

33. Rosenstiel AK, Keefe FJ. The use of coping strategies in chronic low back pain patients: relationship to patient characteristics and current adjustment. Pain 1983;17:33-44.

34. Zung WWK. A self-rating depression scale. Arch Gen Psychiatry 1965;12:63-70.

35. Wallston KA, Stein MJ, Smith CA. Form C of the MHLC Scales: a condition-specific measure of locus of control. J Pers Assess 1993;63:534-53.

36. Ransford A, Cairns D, Mooney V. The pain drawing as an aid to the psychologic evaluation of patients with low back pain. Spine 1976;1:127-34.

37. Waddell G, McCulloch JA, Kummell ED, Venner RM. Nonorganic physical signs in low back pain. Spine 1980;5:117-25.

38. Uden A, Astrom M, Bergenudd H. Pain drawings in chronic back pain. Spine 1988;13:389-92.

39. Chan CW, Goldman S, Illstrup DM, Kunselman AR, O'Neill PI. The Pain Drawing and Waddell's Nonorganic Signs in chronic low back pain. Spine 1993;18:1717-22.

40. Tabachnick BG, Fidell LS. Using Multivariate Statistics, 3rd edn. New York: Harper Collins, 1996.

41. Cronbach LJ. Coefficient alpha and the internal structure of tests. Psychometrica 1951;16:297-334.

42. Cronbach LJ. Essentials of Psychological Testing, 4th edn. New York: Harper Row, 1984.

43. Stauffer RN, Coventry MB. Anterior interbody lumbar spine fusion: analyses of Mayo Clinic series. J Bone Joint Surg 1972;54:756-68.

44. Stauffer RN, Coventry MB. Posterolateral lumbar spine fusion: analysis of Mayo Clinic series. J Bone Joint Surg 1972;54:1195-204.

45. Herron LD, Pheasant HC. Bilateral laminotomy and discectomy for segmental lumbar disc disease. Decompression with stability. Spine 1983;8:86-97.

46. Herron LD, Turner J. Patient selection for lumbar laminectomy and discectomy with a revised objective rating system. Clin Orthopaed 1985; 199:145-52.

47. Herron LD, Turner J, Clancy S, Weiner P. The differential utility of the Minnesota Multiphasic Personality Inventory. A predictor of outcome in lumbar laminectomy for disc herniation versus spinal stenosis. Spine 1986;11:847-50.

48. Herron L, Turner J, Weiner P. A comparison of the Millon Clinical Multiaxial Inventory and the Minnesota Multiphasic Personality Inventory as predictors of successful treatment by lumbar laminectomy. Clin Orthopaed 1986;203:232-8.

49. Uomoto JM, Turner JA, Herron LD. Use of the MMPI and MCMI in predicting outcome of lumbar laminectomy. J Clin Psychol 1988;44:191-7.

50. Herron L, Turner J, Ersek M. et al. Does the Millon Behavioral Health Inventory (MBHI) predict lumbar laminectomy outcome? A comparison with the Minnesota Multiphasic Personality Inventory (MMPI). J Spinal Disorders 1992;5:188-91.

51. Cohen J, Cohen P. Applied Multiple Regression/Correlation Analysis for the Behavioral Sciences, 2nd edn. Hillsdale: Lawrence Erlbaum Associates, 1983

52. Aichison J, Silvey SD. Generalization of probit analysis to the case of multiple responses. Biometrika 1957;44:131-40.

53. Greene WH. Econometric Analysis, 2nd edn. Englewood Cliffs: Prentice Hall, 1993.

54. Hosmer DW, Lemeshow S. Applied Logistic Regression. New York: Wiley, 1989.

55. Cohen J. A coefficient of agreement for nominal scales. Educ Psychol Meas 1960;20:37-46. 
56. Liebetrav AM. Measures of Association. Beverley Hills: Sage Publications, 1983.

57. Siegel S, Castellan NJ. Nonparametric statistics for the behavioural sciences, 2nd edn. New York: McGraw-Hill, 1988

58. Sorensen LV, Mors O, Skovlund O. A prospective study of the importance of psychological and social factors for the outcome after surgery in patients with slipped lumbar disc operated upon for the first time. Acta Neurochirurgica 1987;88:119-25.

59. Turner JA. Coping and chronic pain. In: Bond MR, Charlton JE, Woolf CJ, eds. Proceedings of the VIth World Congress on Pain. London: Elsevier Science Publishers, 1991:219-27.

60. Waddell G, Morris EW, Di Paola MP. A concept of illness tested as an improved basis for surgical decisions in low back disorders. Spine
1986;11:712-9.

61. Bessette L, Liang MH, Lew RA, Weinstein JN. Classics in Spine. Surgery literature revisited. Spine 1996;21:259-63.

62. Waddell G. Evaluation of results in lumbar spine surgery. Acta Orthopaedica Scandinavica 1993;64(Suppl 251):134-7.

63. Nachemson AL. Evaluations of results in lumbar spine surgery. Acta Orthopaedica Scandinavica 1993;64(Suppl 251):130-3.

64. Daltroy LH, Cats-Baril WL, Katz JN, Fossel AH, Liang MH. The North American Spine Society Lumbar Spine Outcome Assessment Instrument. Spine 1996;21:741-9.

65. Block AR. Presurgical Psychological Screening in Chronic Pain Syndromes: A Guide for the Behavioral Health Practitioner. Hillsdale: Lawrence Erlbaum Associates, 1996. 


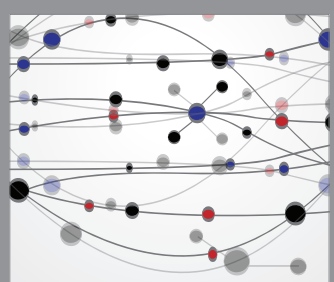

The Scientific World Journal
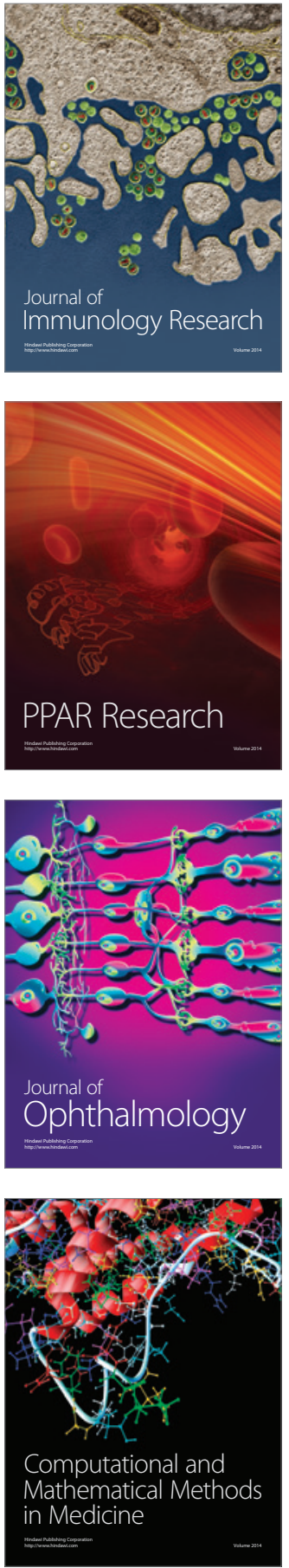

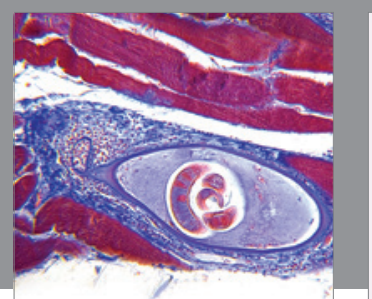

Gastroenterology Research and Practice

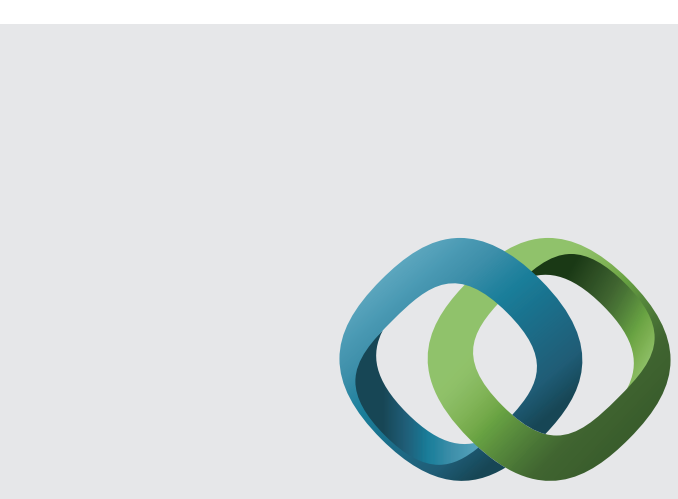

\section{Hindawi}

Submit your manuscripts at

http://www.hindawi.com
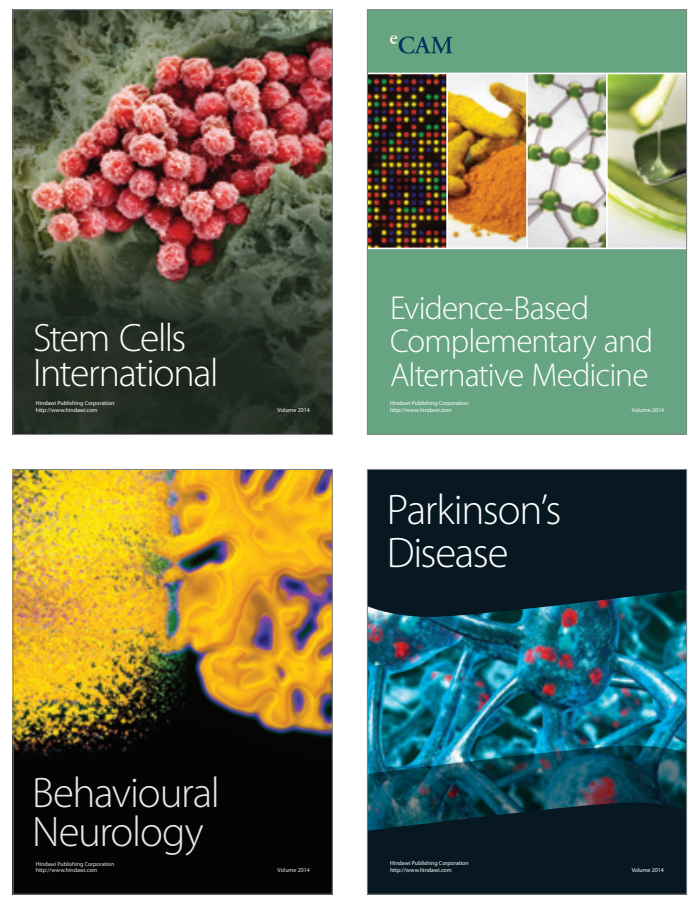
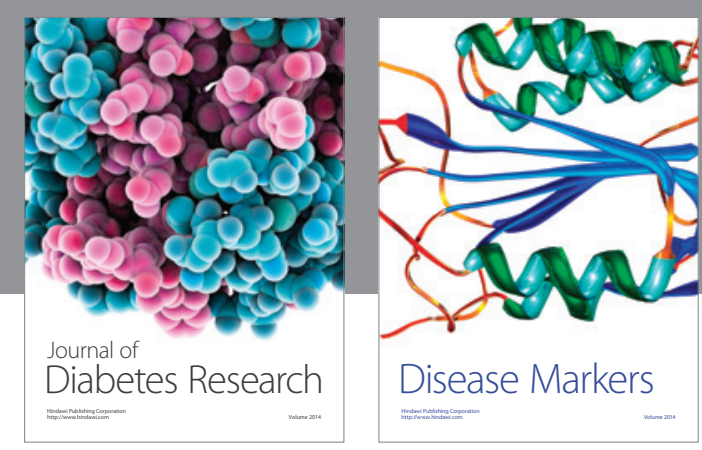

Disease Markers
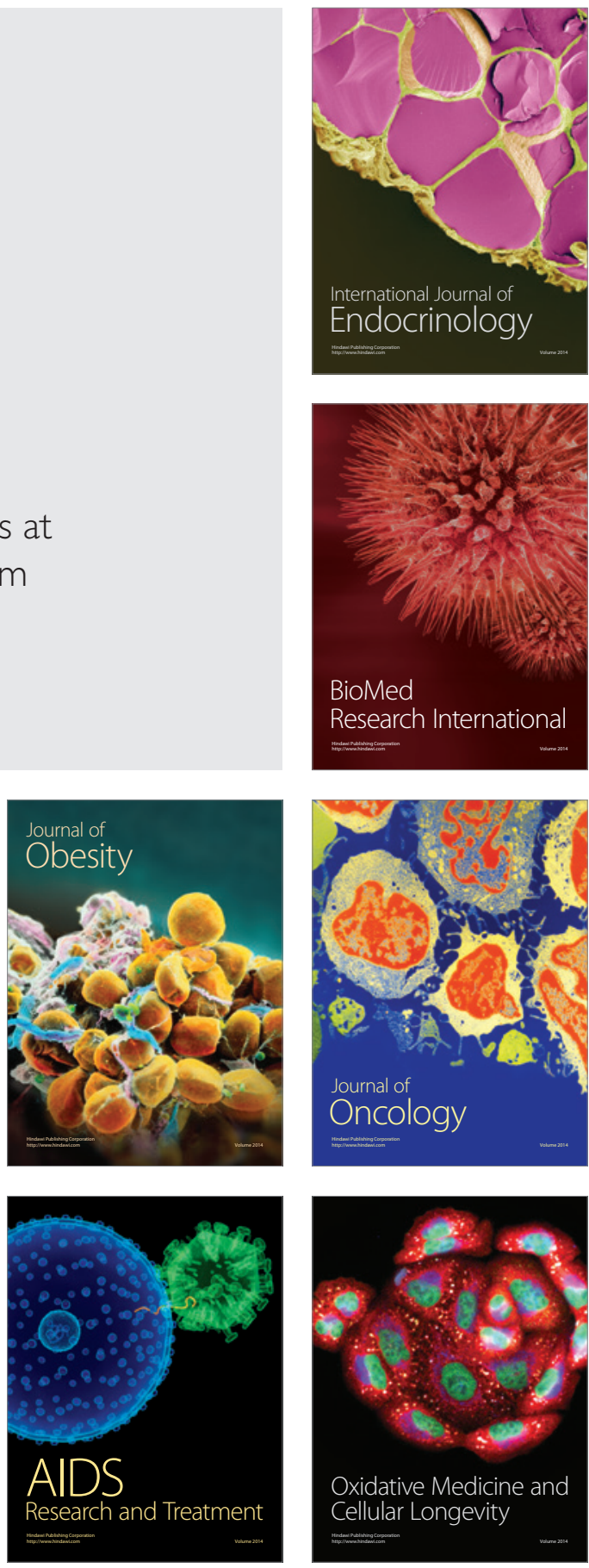